\title{
HarpCl, empowering performers to control and transform harp sounds in live performance.
}

\author{
Balandino Di Donato, James Dooley \& Lamberto Coccioli
}

The goal of our research is to provide harpists with the tools to control and transform the sounds of their instrument in a natural and musical way. We consider the development of music with live electronics, with particular reference to the harp repertoire, and include interviews with six harpists that use technology in their professional performance practice. We then present $\mathrm{HarpCl}$ a case study that explores how gestures can be used to control and transform sound and light projection in live performance with the electric harp. HarpCl draws on research from the areas Human Computer Interaction ( $\mathrm{HCl})$ and Music Interaction Design (MiXD) to extend the creative possibilities available to the performer, and demonstrates our approach to bridging the gap between the performer/composer and the harp on one side, and the technology on the other. We discuss the use of guitar pedals with the electric harp, and the limitations they impose, and then introduce the MyoSpat system as a potential solution to this issue. MyoSpat aims to give musicians control over auditory and visual aspects of the performance through easy to learn, intuitive and natural hand gestures. It also aims to enhance the compositional process for instrument and live electronics, through a new way of music notation for gesturally controlled interactive systems. The system uses the $\mathrm{Myo}^{\circledR}{ }^{\circledR}$ armband gestural controller, a device to control live sound processing that is non-invasive to instrumental technique and performer. The combination of these elements allows the performer to experience a tangible connection between gesture and sound production.

Finally, we describe the experience of Eleanor Turner, who composed and performed The Wood and the Water using MyoSpat, and we conclude by presenting the outcomes from HarpCl workshops delivered at Cardiff Metropolitan University for Camac Harp Weekend, Royal Birmingham Conservatoire's Integra Lab and Southampton University.

Keywords: Harp, Music Performance, Live Electronics, Sonic and Music Interaction Design, Interactive Audio, Motion Sensor 


\section{Introduction}

In live electronic music, 'technology is used to generate, transform or trigger sounds (or a combination of these) in the act of performance' (Emmerson \& Smalley, 2001, p.p 59-60). Live electronics covers a vast array of practices, and has a history dating back to the midtwentieth century. From the moment acoustic instruments could be amplified, technology has had the capability to control and transform their sound in unprecedented ways.

Although we may commonly associate computers with contemporary electronic music, early live electronic music made use of purpose-built hardware devices to process sounds. Stockhausen's Mixtur (1964) and Mikrophonie (1964/1965) made use of one such device called a 'ring modulator', where orchestral and percussion instruments respectively are sonically transformed beyond recognition during performance. Contemporaneous with Stockhausen, a number of devices aimed at electric guitarists were being developed. WEM's COPICAT Super IC-300 ${ }^{\circledR}$ (1958) allowed guitarists to experiment with delay and echo effects, whilst ten years earlier DeArmond's Trem Trol $800^{\circledR}$ (1948), capable of tremolo effects, presented the first commercially produced standalone effects unit.

There are several successful historical examples of interaction between harp and electronics - one for all is the extraordinary harp part in Pierre Boulez's Répons (1988) - but the repertoire for solo harp and live electronics is rather limited. It is worth mentioning Javier Álvarez's Acuerdos por diferencia (1989), Kaija Saariaho's Fall composed in 1991, Echappées (for celtic harp) by Jean-Claude Risset written in 2004, Éclosion by Malika Kishino (2005), Raphaël Cendo's Octa 7 on a choreography by Olivia Grandville (2007), History of My Instrument for harp, electronics and video by Simon Steen-Andersen (2011) and Roll...'n roll...' $n$ roll for prepared harp and electronics by Georgia Spiropoulos (2015). Interestingly, in 1996 Luciano Berio embarked on a project to create new versions with live electronics of Sequenza II for harp, Sequenza VI for viola and Sequenza $X$ for trumpet. Berio's idea was to explore electronics as a means to project the sound of the solo instrument, and reveal hidden aspects inherent in the musical material. This was akin to what he had done in his Chemins, where the original Sequenzas were 'translated' and expanded into the orchestral domain ${ }^{1}$. Specifically regarding the harp Sequenza, Berio's intention was to use the electronics as a sort of magnifying lens, in order to amplify minute details of the sound, and project them in space. This ambitious project was carried out at Tempo Reale ${ }^{2}$ but was unfortunately left unfinished, leaving the electronic Sequenzas in different stages of partial completion.

With the development of personal computers in the 80s, audio programming environments and software started to emerge, quickly becoming the tool of choice for composers. Popular visual programming environments such as $\mathrm{Max}^{\circledR}$ and Pure Data made interactive computer music possible (Wang \& d'Escrivan, 2011). More recent software applications such as Live ${ }^{\circledR}$ and Integra Live provide musicians with a more intuitive and user-friendly interface. These are all powerful tools, with the ability to design complex systems to manipulate sound in performance. However, a disruptive musical experience can occur if the performer has a low level of familiarity with the technology, and the two become divergent (Bullock, Coccioli, Dooley \& Michailidis, 2013). Introducing prosthetic elements such as pedals and sensors can exacerbate this problem (McNutt, 2003), presenting the performer with a sense of disconnection between physical action and sonic response. 
As part of this study, we interviewed a number of professional harpists that have worked with live electronics. Their range of experiences include using guitar pedals, audio programming environments and gestural controllers, demonstrating that a great number of skills and techniques are required to approach this discipline with confidence. We identify the creative opportunities technology offers to composers and performers, as well as its problems and disruptive aspects.

\section{Interviews with six harpist working with live electronics}

As recognised by the editor of this special issue, there is very limited literature specifically discussing the use of technology in harp performance. We conducted a series of six interviews with professional harpists using technology in their performance practice, in order to learn more about their relationship with technology. The harpists interviewed were Audrey Herrer, Arnaud Roy, Hélène Breschand, Jennifer Ellis, Sofia Asunción Claro and Una Monaghan.

The interviews were semi-structured, with participants freely responding to questions based around a number of themes concerning harp technique and performance, live electronics and gestural controllers, and their general experiences of working in this area. A common theme to emerge from the interviews was that of learnability with regard to technology and electronic systems. Most reported that technology requires 'too much time' to be learnt, and demands time away from music making; in some cases, the interviewee felt the time invested in learning technology for a limited number of performances was not well spent.

When I learn a new technology I spend a lot of time on it, and then I maybe perform 45 times with it, and sometime it is not worth to spend that much time on it.

Arnaud Roy, 2017 (personal communication)

Audrey Herrer, Hélène Breschand and Jennifer Ellis highlight the importance of practicing technology in order to embed it cohesively in their musical practice, considering the study of technology equal to that of any other instrumental technique. Sofia Asunción Claro shares this sentiment in the following statement:

My experience with electronics and technology was very pleasant, I did enjoy it. I never had problems because I was practicing to have things under control.

Sofia Asunción Claro, 2017 (personal communication)

Similarly, Audrey Herrer emphasises the importance of practice:

Using technology is like learning anything else. It is like learning a passage on the piano. It's a matter of practice. It's just something that develops through practice. It's like anything.

Audrey Herrer, 2017 (personal communication) 
Most of the interviewees had experience of using guitar pedals in their practice, with the above observations describing how study and practice were key to developing confidently the muscle memory needed to trigger effects precisely. Hélène Breschand consider them 'a musical instrument', 'an extension of the harp' (personal communication) . The freeze pedal was the most used among the interviewees. As the harp sound is characterised by a short sustain, being able to make the sounds indefinitely longer has a particular appeal to harpists.

Arnaud Roy takes an original approach to the freeze pedal in The Families (Lumeris Theme) ${ }^{3}$, where he combines the use of the pedal with audio transformations driven by the Leap Motion ${ }^{\circledR}$ gestural controller ${ }^{4}$. Specifically, he uses the freeze pedal to create 'pad' sounds, and consequently manipulates them using the Leap Motion ${ }^{\circledR}$.

The majority of the interviewees described pedals as reliable devices that make music technology more accessible. Jennifer Ellis underlined the fact that harpists are very skilled in moving their feet, and potentially have already the skills required to integrate guitar pedals into performance confidently and with reduced practice time. However, the use of guitar pedals with a pedal harp can potentially disrupt the performance, as the feet are required to perform chromatic changes. This is one reason why Ellis believes that gestural technology could be a solution for designing a closer interaction with the audio processing. Roy supports this idea when talking about his experience with the Leap Motion ${ }^{\circledR}$ :

I think it's a very interesting way to perform, to have good control on your sound and it's very accurate. I think the Leap Motion it's accurate and I can do whatever I want with it. Sometime it's a little buggy but I feel comfortable with it. [...] I think it is very enjoyable. When I started working with the Leap Motion I was amazed by the way my hands could control sound. It's magical. It's like you are feeling the sound, like if you are a sculptor. It's magical because the audience perceive that when you move your hands the sound changes. Maybe another idea would be to have lights, people love that.

Arnaud Roy, 2017 (personal communication)

Here Roy acknowledges the importance of communicating to the audience the action and response between physical gesture and sonic result, through the performer's gestural interaction with the technology. Other interviewees shared the idea that gestural technology represents a form of visual feedback for the audience to experience and engage with the musical performance. Asunción Claro describes it:

[talking from the audience point of view] I think it is interesting to listen [to sound transformations as] the result of my own movement, [it] is quite unexpected that you do some movements and the sounds will change, that modify the sound but you are not playing the instruments.

Asunción Claro, 2017 (personal communication)

In response to the question, 'Do you design gestures considering the visual impact it would have on the audience or do you design them to facilitate the musical performance?' Una Monaghan says: 
Both of them. I work on all these things in parallel. If I want something to work with a gesture and that's going to happen, I'm aware of the visual feedback of the audience. [...] Sometime I push the button on the motion sensor and I want the audience to see it, sometime I don't want to show that, so I don't make it obvious. But other times I want them to know what's going on. So I make it more obvious. [...] It's always a parallel process between what's practical and what is compositional process. [...] I always think about the composition, performance, practicality of the software and coding in parallel. I work with these strands as important as the others.

Una Monaghan, 2017 (personal communication)

In Roy's live performance of FlyByNo The Families (Lumeris Theme), a Leap Motion ${ }^{\circledR}$ controlled by his left hand is placed on a laptop. From an interaction point of view, the Leap Motion ${ }^{\circledR}$ does not solve all the issues that harpists encounter during live electronic performance. A number of issues can arise, such as having to move the hands away from the instrument, disallowing the performer to play the instrument directly. A similarly awkward situation can occur when performers have to adapt their instrumental technique in response to the demands of the device's motion capture capabilities.

Ellis notes her experience of this whilst using IRCAM's MO ${ }^{\circledR}$ (Modular Musical Objects device $^{5}$ ) for performing Weav-Weav-Weaving I, II and $I I I^{6}$. Ellis took an empirical approach to developing the way in which she could use the device. Attaching the device to her left arm using a smartphone support band, Ellis used $\mathrm{Max}^{\circledR}$ to develop meaningful mappings between movement and audio processing for Weav-Weav-Weaving. ${ }^{7}$ Una Monaghan describes a similar approach to developing gesture-controlled audio processing, having used IRCAM devices as well as the $\mathrm{X}-\mathrm{IMU}^{\circledR}$ device by $\mathrm{X}-\mathrm{IO}$ Technologies ${ }^{8}$.

Of the harpists interviewed, a preference for using the left hand to control sound processing emerges, whether this be turning a dial on a guitar pedal or using a gestural device. With the harp positioned on the right shoulder, the left hand has more freedom to move and is used to dampen the strings. Both Roy and Monaghan discuss this; Ellis adds:

I chose the left arm because there is generally far more space on my left arm between my hand and the metal action plate above my hand and the wood soundboard below my hand on the left side of the harp than on the right side of the harp. When my right hand plays high, it needs all the space it can get and even a small sensor could end up knocking against the board or the metal action plate of the harp.

Jennifer Ellis, 2017 (personal communication)

This approach for establishing mapping strategies facilitates interaction with the electronic audio processing in a way that is sympathetic to standard harp technique. Roy's current work with the French harp manufacturer $\operatorname{Camac}^{\circledR}$ on a new MIDI harp examines ways to manipulate the sounds through an interaction design that builds on instrumental technique. He does, however, report how the MIDI harp presents difficulties in creating meaningful mappings, and how unnatural it is to manipulate sounds or play virtual instruments with it. Comparing the MIDI harp to gestural controller technology, he describes the latter as 'more 
easy to set up, more easy to use and more enjoyable', further saying how attaching the Leap Motion ${ }^{\circledR}$ to the body of the harp would facilitate a method of gestural interaction that does not require the hands to move away from the instrument. Camera based devices have been used also by Asunción Claro. She performed using a camera to control and transform the sound in Sound Shapes, by Lars Graugaard ${ }^{9}$.

In addition to choosing the right technology to support the gestures inherent in performing a specific musical work, mapping strategies play an equally important role in creating coherent connections between action and response when using interactive technology. In her Weav-Weav-Weaving I, II and III for harp and interactive live electronics ${ }^{10}$, Ellis demonstrates her use of the same devices to manipulate the sound of the harp with different interaction design and mapping strategies in each work. The technology becomes composition-specific, adapting to the type of harp and the required instrumental technique for each work, especially concerning movements of the feet when playing the pedal harp.

Developing strong, lucid connections between instrumental technique, gesture, technology and musical output emerges as a recurring theme throughout the interviews we conducted. Employing an approach that considers these aspects can create musical experiences that are meaningful for performer and audience alike. The following section discusses the MyoSpat system $^{11}$ in the HarpCl project as a method to exploit gestures originating in instrumental technique to control sound transformations. We discuss how this approach strengthens the connection between the actions of the performer and the sonic response, allowing performers to control sound through an embodied musical interaction.

\section{The HarpCl project}

\section{Introduction to HarpCl and MyoSpat}

$\mathrm{HarpCl}$ explores the use of electronic devices to control and transform sound and light projections when performing with the electric harp. The project seeks to extend the creative possibilities available to the performer, drawing on research from the areas of Human Computer Interaction $(\mathrm{HCl})$ and Music Interaction Design (MiXD). We consider the role of the performer/composer, the tensions and limitations inherent in live audio processing and the impact on the audience experience. We introduce MyoSpat, an interactive system that uses hand-gestures to control and transform timbral and spatial properties of the sound and light projections, as a potential solution to the issue. MyoSpat can also facilitate the annotation of the electronic part in the score, through a new type of music notation for the control of gesture-based interactive systems ${ }^{12}$. The next section presents an analysis of the gestures commonly found in harp performance, and shows how MyoSpat's user interaction was designed in collaboration with Eleanor Turner. An evaluation of the user experience of the system is presented, followed by a discussion of Eleanor Turner's experience of composing and performing The Wood and the Water for harp and MyoSpat.

\section{Gestures during harp performance}

To analyse the harpist's gestures we use the taxonomy adopted by Jensenius et al. (2009) which divides musical gestures into sound-producing, sound-facilitating, communicative and 
sound-accompanying gestures. Sound-producing gestures are those responsible for the production of the sound. Communicative gestures express the intentions of performers to the audience or other co-performers. Sound-facilitating gestures enhance sound producing, for instance to keep the tempo, to reach the strings or to control a note. Soundaccompanying gestures do not play any role in the production or control of sound. All gestures are distinguishable, cross-related, and influence each other (Desmet et al., 2012). Context and body posture are important to consider when analysing gestures (Leman, 2010; Visi, Schramm \& Miranda, 2014), with gestures performed when standing being more appreciable (Visi et al., 2014).

\section{Body movements in harp performance}

Results from a gestural interaction analysis during harp performance carried out by Chadefaux et al. (2012), showed that (i) the global posture of harpists is very stable during playing, (ii) the relationship between arm and limbs is constant, (iii) the shoulder represent a fixed point where sound-producing gestures have their origin and, (iv) hands performs more accentuated movements (Chadefaux, Wanderley, Le Carrou, Fabre \& Daudet, 2012b). They conclude by saying that most of the harpist's interpretation is delivered through movements of the hands. A similar, later study (Chadefaux, 2013) specifically analysed and compared shoulder, elbow and wrist movements among three participants playing Debussy's Danse Profane. From this analysis, they estimated that the shoulder is the joint that performs most of the work during performances, secondly the elbow, and ultimately the wrist. Other works (Chadefaux, Le Carrou \& Fabre, 2013; Le Carrou, Wahlen, Brasseur \& Gilbert, 2008) reported the importance and commonalities among performers of hand and finger gestures.

\section{Sound-producing gestures in harp performance}

The main sound-producing gesture in harp performance is the plucking technique. It can be divided into three temporal stages: stick, slip, and free oscillation phase (Chadefaux, 2013; Chadefaux, Le Carrou, Fabre \& Daudet, 2012a; Chaigne \& Kergomard, 2016; Pavlidou, 1997). In the stick phase, the performer pulls the string until a certain threshold is reached. Here the performer releases the string (slip phase) and lets the string oscillate freely (free oscillation phase). Another sound producing gesture is the brushing technique, and involves the performer sliding the fingers very fast across a group of notes. The hand should assume a standard position, and each finger should close after release. This is a standard technique used for playing an ascending or descending Aeolian chord (see Figure 1). 

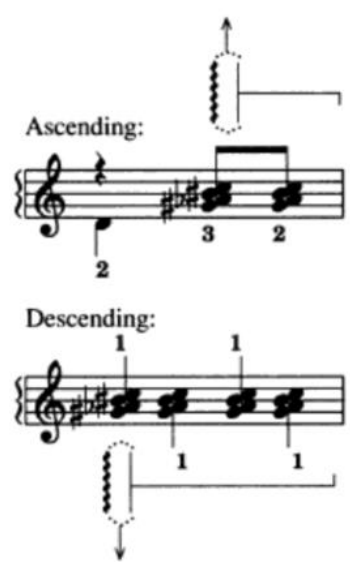

Figure 1. Aeolian chord playable using the brushing gesture. Image retrieved from Kondonassis (2006).

\section{Sound-facilitating gestures in harp performance}

The most commonly employed sound-facilitating gesture in harp performance is the raising gesture. It is performed by gradually closing the hand from the plucking position into a fist, while raising the wrist. This gesture can be enacted using the French or Salzedo methods (Huang, 2011). Renié's raising gesture (French method), is performed by an outward wrist movement, either with or without the arm. This gesture facilitates the control of the sustain (Huang, 2011). Salzedo's raising gesture is executed with the elbow at a fixed point, raising the closed hand with complete control. The Salzedo method also includes indications concerning facial expression. According to Salzedo, during the rising gesture the performer should not look at the hands, but should keep looking in the direction of the soundboard or the strings, and listen accurately until the sound is extinguished; to this extent the raising gesture improves tone, technique and musical interpretation. This movement also enhances the muscular, mental relaxation and physical respiration during performance (Dennett, 2015). The raising gesture helps to decrease the noise produced by the premature replacement of the fingers on the strings (Kondonassis, 2006). It is interesting to consider the aesthetic aspect of this gesture:

Since the instrument [the harp] does require necessary gestures, these gestures should be correct not only functionally but aesthetically as well. Music is meant to be heard, but also to be looked at - otherwise radio would long ago have supplanted the concert stage which, fortunately, it has not. Like the orchestral conductor, the harpist must learn how to externalize music. This he does through his gestures which should be inspiring and not dry; these gestures should emphasize and not negate the intent of the music. On this basis, I give my students training which permits them to play aesthetically as well as musically. I explain to them that the harpist should consider himself like the orchestra while his gesture-making hands are the conductor who calls forth his playing and depicts phrases through motion.

(Salzedo, 1952 pp.9)

Salzedo then continues commenting on the importance of the raising gesture: 
The basic harpistic gesture is the raising of the hands slowly and with complete control. Once this ascending gesture has been mastered, the perfectly controlled hands are then at your service for all kinds of touches. When the hands react sensitively to the various rhythmical and emotional requirements of music, there is no difficulty in rendering a composition as intended by the composer. This slow, controlled raising of the hands grows out of complete relaxation - first mental, then muscular aesthetically accomplished. For example: to prevent tenseness, some harpists recommend dropping the hand wrist up. This is an ugly gesture. I cure tenseness by stressing no particular gesture as law, but by inviting mental relaxation and, for a while, avoiding loud or fast playing.

(ibid., pp.9)

The importance of sound-facilitating gestures is further confirmed by Chadefaux et al., demonstrating through kinematic analysis of the harpists' gestures that a high level of hand and arm activity occurs after the plucking action (Chadefaux et al., 2012b).

\section{MyoSpat System}

MyoSpat is an interactive audio-visual system that aims to empower musicians by allowing them to control and transform sound and light projections in musical performance through a natural interaction. MyoSpat uses the $\mathrm{Myo}^{\circledR}{ }^{\circledR} \mathrm{armband}^{13}$ as gestural controller, Myo Mapper ${ }^{14}$ software, and the Pure Data $(\mathrm{Pd})^{15}$ visual programming language as gesture recognition and audio-visual engine. The system's design is informed by human-computer interaction $(\mathrm{HCl})$ principles, tangible computing, and embodied, Sonic and Music Interaction Design (SiXD, MiXD). Here we describe the development of MyoSpat, and how the work conducted with the harpist Eleanor Turner influenced its design and implementation.

\section{Interaction Design and Audio-Visual Processing}

The approach adopted to develop the design of MyoSpat's interaction was determined by the necessity to fulfil three aims: (i) easy to learn, (ii) usable during musical performance without interfering with instrumental technique, and (iii) enabling a strong relationship between arm/hand gestures and audio-visual feedback, leading to embodied musical interactions. Embodied musical interactions are defined here as metaphors of common interactions in the context of musical performance (Wigham \& Boehm, 2016; Wilkie, Holland \& Mulholland, 2009; 2010).

MyoSpat allows performers to control and transform the sound through four audio signal processors, namely: spatialiser, reverb, pitch shifter, and an amplitude modulator chained with a delay. The input audio signal can be processed by orientating the arm, on which the Myo ${ }^{\circledR}$ armband is worn, towards three different directions, by contracting the forearm's muscles and performing a throwing gesture. Performers can also control visual feedback through lighting effects. The sound is spatialised using a quadraphonic audio system placed around the audience; the lighting system is set up on stage projecting the light towards the performer and the environment surrounding them. 


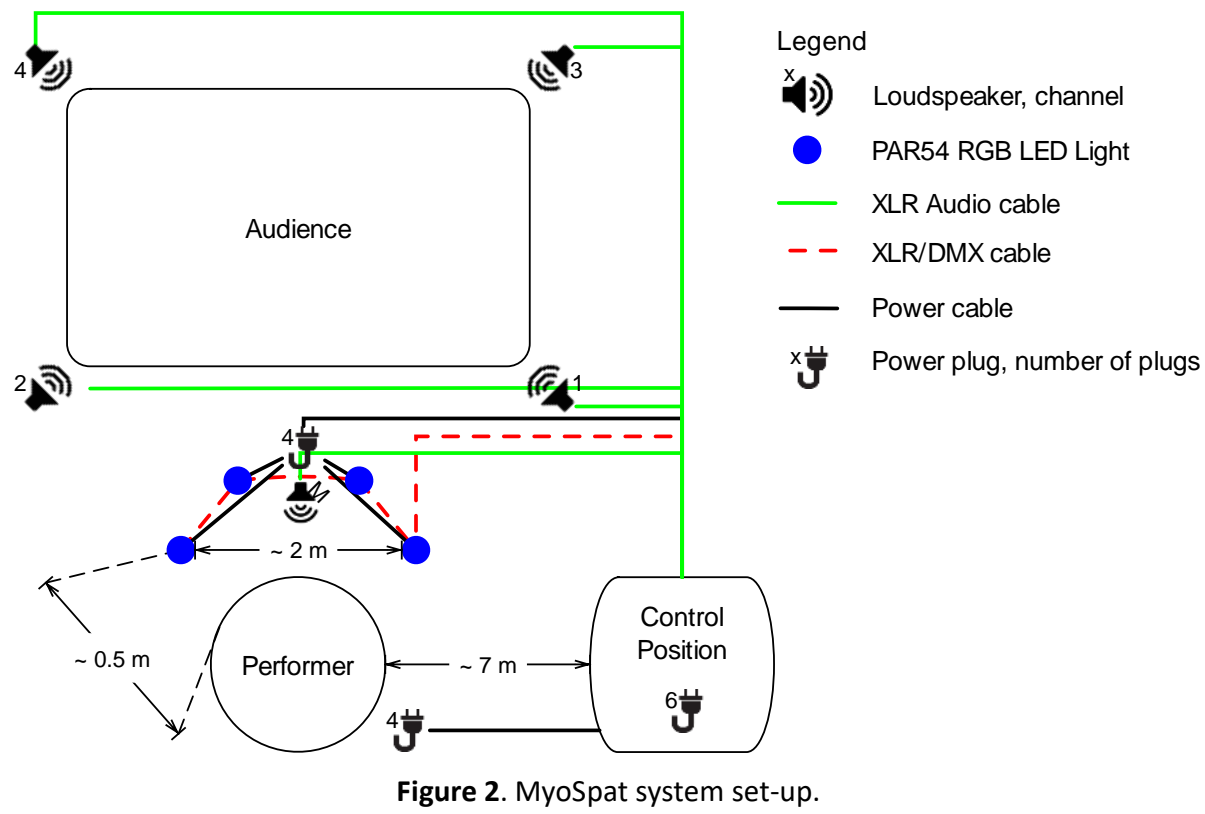

MyoSpat's interaction design can be seen in Figure 3, which shows the discrete directions in which the arm has to be oriented, assuming the performer wears the $\mathrm{Myo}^{\circledR}{ }^{\circledR}$ armband on the left arm. If the performer wears the $\mathrm{Myo}^{\circledR}$ on the right arm Areas 1 and 2 in Figure 3 need to be reversed.

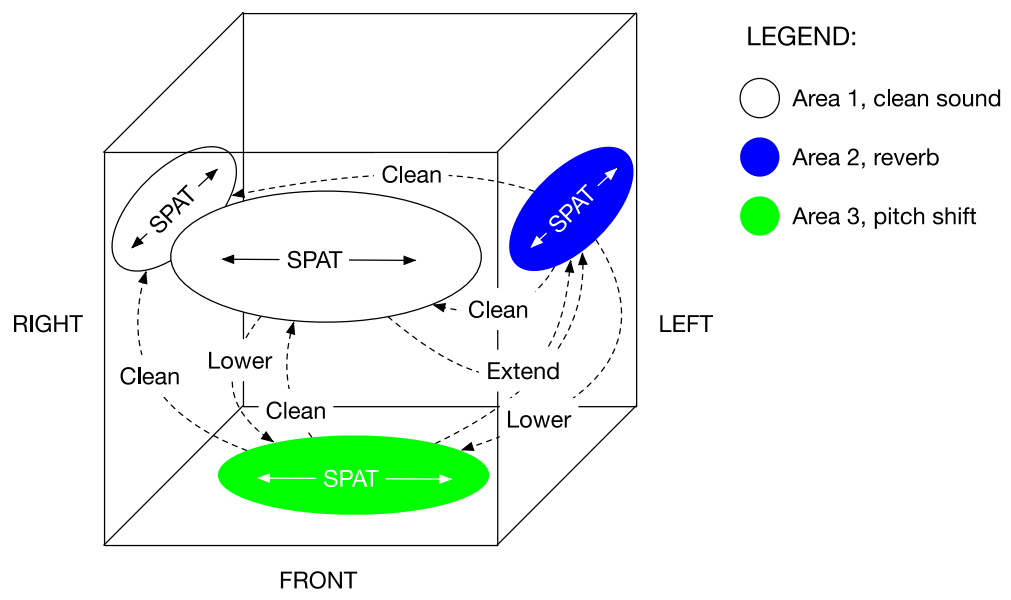

Figure 3 MyoSpat interactive areas if wearing the $\mathrm{Myo}^{\circledR}$ armband on the left arm.

\section{Gestures used in MyoSpat Interaction Design}

\section{Clean gesture}

By orienting the arm frontwards, upwards, or inwards towards the chest (Figure 3, Area 1), it is possible to obtain a clean sound. This movement also changes the colour of the lighting to white. This gesture is then called clean gesture as it removes any processing from both sound and lighting. 


\section{Extend gesture}

By orienting the arm outwards on the horizontal plane (Figure 3, Area 2) the sound is processed through a reverb. This gesture and the associated audio processing were designed and implemented when mapping the raising gesture onto sound transformation parameters. The raising gesture is considered one of the most important gestures in harp performance for its functional and aesthetic aspects. It helps the performer to control the sustain of the sound, and is partially responsible for the rhythmic and expressive aspects of the performance. However, as in many other chordophones, the sustain of the harp cannot be finely controlled or extended after the string has been plucked.

The intention here was to augment the performer's level of control over sustain and decay, allowing them to extend the sound of the harp to an unnatural length. A long-tailed reverb is applied to the sound, and the wideness of the rising gesture controls the early echoes and late diffusion characteristics of the reverb. Wideness is represented by the angle $\alpha$ formed by the wrist, the performer, and the harp in the horizontal axis (Figure 4). Thus, the further the hand moves away from the body of the harp, the longer and more distant the sound will be.

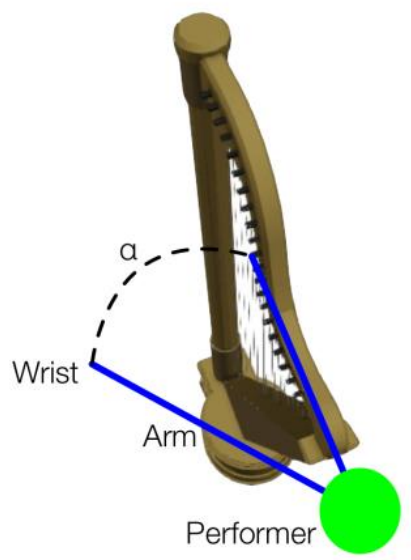

Figure 4 Angle formed by the harp and the performer's arm.

\section{Lower gesture}

By orienting the arm downwards (Figure 3, Area 3), the user can transpose the pitch of the harp an octave lower. This interaction has been considered by taking into account findings from Wilkie et al. (2009, 2010), where the relationship between pitch and verticality (updown) is posited as a strong conceptual metaphor in interaction design. When this gesture is performed, the lighting colour becomes green.

\section{Crumpling gesture}

With MyoSpat, harpists can manipulate the sound by moving the fingers rapidly, as if they were crumpling paper. The gesture is mapped to an amplitude modulator chained to a delay line. This type of audio interaction was first designed and implemented when working on a Mixed Reality experiment (Di Donato \& Bullock, 2015), where a crumpling paper gesture was used to trigger audio processing that sonically simulated this gesture (see video ${ }^{16}$ ). During an analysis of the activity of the forearm's muscles when harpists pluck the strings, we noticed that they engage the same group of muscles that contract when crumpling paper. Accordingly, we mapped the plucking gesture to the activation and control of the 
amplitude modulation and delay effect. Specifically, the tenser the muscles, the shorter the delay time, and the louder the sound.

\section{Pointing gesture}

Pointing the arm allows the performer to move the sound towards the direction they are pointing to. This interaction builds upon research driven by Streeck et al. (2011). They describe how two people can replace words with gestures during verbal communication. After analysing a conversation between two people, they reveal the importance of pointing gestures to refer to physical objects in space that were the subject of the conversation (Streeck, Goodwin \& LeBaron, 2011). The pointing gesture allows a form of spatialisation of the sound, depending on the number and location of the speakers available. To enhance the spatial perception of the sound, spatialisation cues are utilised to control the brightness of the lights. In particular, when the sound is coming from one of the speakers, the light associated with it becomes brighter.

\section{Throwing gesture}

Inspired by the work conducted by Bullock and Di Donato (2016), where sound is considered a tangible entity that can be manipulated and moved into the virtual space (see video ${ }^{17}$ ), Myospat allow performers to generate sound spatialisation trajectories. These are generated by emulating the gesture performed for throwing away an object. Specifically, the stronger the gesture the longer the trajectory lasts.

\section{MyoSpat score notation}

Notating the electronic part of a musical work has always been challenging. Eimert et al. (1954) propose methods to realise an 'acoustic' representation of the electronic processes. They also state the fact that the notation in the score needs to support the prevailing musical culture at the given time (Eimert, Enkel \& Stockhausen, 1954). Today, the electronic component in music is becoming common, and audio processing techniques are increasingly common knowledge among musicians. In the context of gesture-controlled technology, a notation that tried to represent the outcome of the audio processing would easily result in confusion. A better option would be the use of clear indications for the gestural interactions that the user needs to perform. A possible notation for MyoSpat was developed during the collaboration with harpist Eleanor Turner, and is presented in Table 1 below. It focuses on the gestures activating the audio processing rather than on the resulting sound.

Table 1. MyoSpat's gesture notation symbols.

\begin{tabular}{|c|c|c|c|c|c|}
\hline Gesture/Effect & Activate & Deactivate & Hold & Modulate & Legend \\
\hline $\begin{array}{c}\text { Clean } \\
\text { Clean Sound }\end{array}$ & & & & & $\begin{array}{l}x=\text { duration in seconds } \\
y=\text { velocity, fast }(f), \text { medium }(m), \text { slow }(s)\end{array}$ \\
\hline $\begin{array}{l}\text { Extend } \\
\text { Reverb }\end{array}$ & & & & & $\begin{array}{l}x=\text { duration in seconds } \\
y=\text { velocity, fast }(f), \text { medium }(m), \text { slow }(s)\end{array}$ \\
\hline$\underset{\text { Delay }}{\text { Crumpling }}$ & & & & & $\begin{array}{l}x=\text { duration in seconds } \\
y=\text { strength, strong }(f), \text { medium }(m), \text { weak }(s)\end{array}$ \\
\hline $\begin{array}{l}\text { Lower } \\
\text { Pitch Shift }\end{array}$ & & & & & $\begin{array}{l}x=\text { duration in seconds } \\
y=\text { strength, strong }(f), \text { medium }(m), \text { weak }(s)\end{array}$ \\
\hline
\end{tabular}


The Wood and the Water

The Wood and The Water is a piece for electric harp and live electronics, composed and performed by Eleanor Turner using MyoSpat. Turner created the piece in close collaboration with Balandino Di Donato working at Integra Lab, the music interaction design and research group based at Royal Birmingham Conservatoire. Turner's aim was to express and communicate some of her personal experiences through an original type of musical poetry. The first step was writing down the foundation poem on paper, to establish what she wished to express. Then, using British Sign Language (BSL), it evolved into a more descriptive and expressive poem that she could sign and play on the harp. The simplest musical gestures in the piece are BSL signs that begin on the harp with the plucking of the strings to create the sound, and are completed away from the strings. In fact, they often continue for a long time away from the strings, and even away from the instrument - above, around, behind, underneath and to the side of the harp, enabled by the MyoSpat sound spatialisation and delay.

Aside from those exact signs that create the poem, the music sets the scene of walking through a forest, hearing the feet scrunching through the leaves, atmospheric sounds coming from all around, and being alone with one's own thoughts. A connecting musical motif takes us further on our walk through the forest; a break from the signed poem and complex electronic effects. The most intense moment in the piece uses spatialisation, all the gesture-controlled effects and signed poetry, brought about by the discovery of a pool of water that calls for the author's honest, personal reflection. The rhythmical, spoken word and music passage that follows is Turner's impassioned response to this challenge, and is dense with electronic effects and the complexity of words and music angrily spilling out all over each other.

\section{MyoSpat for harp performance}

In addition to musical performances, Di Donato and Turner delivered several harp workshops with MyoSpat. The workshops took place at Royal Birmingham Conservatoire, during the Camac Harp Weekend 2017, and at the University of Southampton. On average, attendees were able to try MyoSpat for five minutes each. The behaviour and comments of the attendees were observed and noted, and thirteen participants completed User Experience Questionnaires (UEQ) (Rauschenberger, Schrepp, Perez-Cota, Olschner \& Thomaschewski, 2013).

\section{Observations}

Observations from the workshops confirm that MyoSpat is easily learnable, and applicable to most harp techniques. The crumpling and the throwing gestures were the only ones that attendees had to practice more, and had more difficulty in adapting to their playing technique. In particular, performers were not able to control finely the contraction of the forearm's muscles and the resulting audio effect.

Interestingly, the limitations imposed by MyoSpat's interaction design, on the one hand, and by the harp's characteristics on the other, pushed performers to manipulate the sound by 
taking advantage of the harp geometries. For example, Eleanor Turner manipulates the sound using amplitude modulation (AM) and delay effects by contractions of the arm's muscles, caused by pressure on the body of the harp. She also found solutions for spatialising the harp sound in any direction by moving the arm over the body of the instrument (see Figure 5).

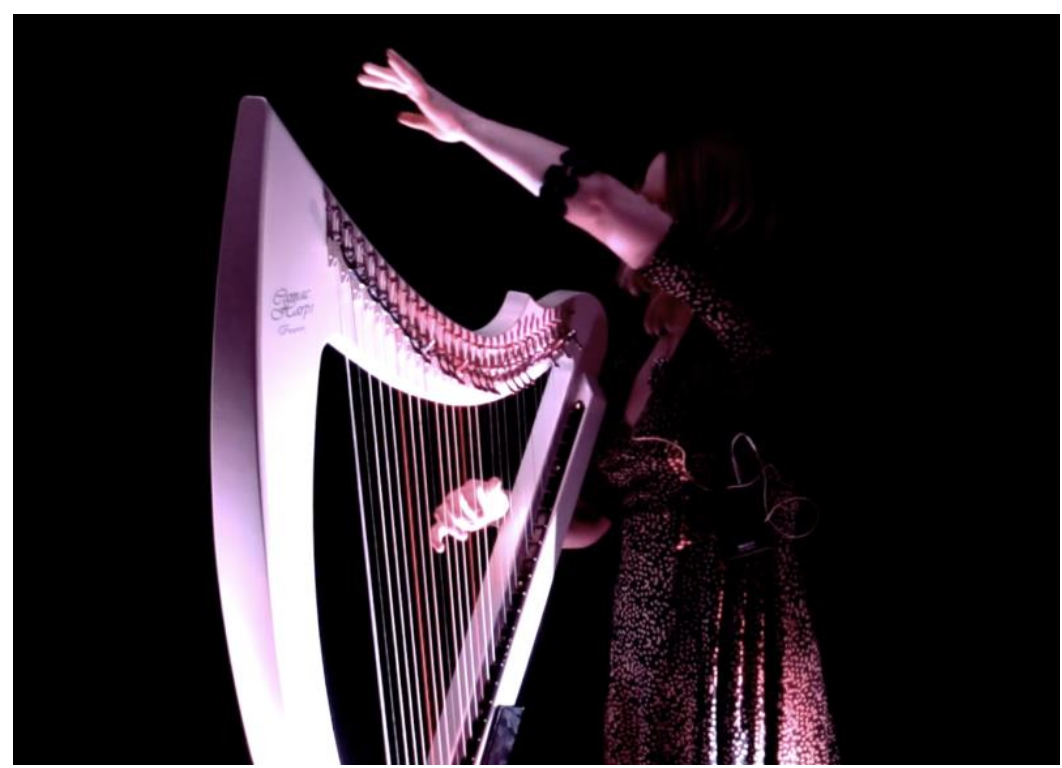

Figure 5. Eleanor Turner spatialises the sound overcoming the limitations imposed by the physicality of the harp.

In another instance, a participant of the workshop at the University of Southampton developed new gestures by putting pressure with her arms on the body of the harp to generate new sounds. The resulting sounds were then processed using MyoSpat.

\section{Verbal comments}

Most of the comments of the attendees were made when performing the crumpling gestures. Through such interaction they felt like playing their own body in conjunction with the harp.

I feel like playing my body, like if I could control the harp sound through my inner self. This makes me have a new intimate relationship with the instrument and the music.

Eleanor Turner (Birmingham, 2017, personal communication)

This armband gives me the possibility to feel the sound through my muscles.

Workshop's attendee (Cardiff, 2017, personal communication)

This makes me more conscious of my instrumental technique.

Workshop's attendee (Birmingham, 2017, personal communication)

After composing The Wood and the Water, Eleanor said:

When I first met Balandino, I had been playing the electric harp for twelve years, making looped pieces using effects, but it didn't feel real. Compared to the responsiveness and varied timbres of the acoustic harp, I was severely 
limited with my basic set up. I wanted to create relevant music to express myself and something of the world today, and I had a dream of being like Björk; collaborating with sound designers and creating an other-worldly amplified show with emotional impact. Until I tried MyoSpat, that concept could not have been further away. MyoSpat has transformed my experience of playing the electric harp. I was trapped in a solitary world of rigid loops and twiddling dials on pedals, whereas now I can move freely, incorporating sign language and spoken word whilst playing the harp. I am hooked on $\mathrm{HarpCl}$ and want to write a whole show using it: what I'm capable of musically and expressively is finally converging with what I'm actually able to achieve! Working with Balandino has given me a direct means of communicating with the audience through a more physical performance style and the use of multiple effects and lights, intrinsically linked with the musical creation.

Eleanor Turner (Birmingham, 2017, personal communication)

Similar comments were also reported by pianist Sarah Nicolls, when playing Suspensions by Atau Tanaka (Nicolls, 2010; 2011). In particular, she was able to process the sound of the piano by engaging and disengaging muscles of her arms during performance. In this video ${ }^{18}$, we can clearly see how mid-air gesture suddenly becomes more meaningful for both performer and audience, through the sonification of electromyographic (EMG) data.

\section{Conclusions}

From our experience working with harpists and using MyoSpat, we are convinced that there is great potential in a system that empowers performers to express themselves through a natural, embodied interaction. The ability to detect arm gestures with a high degree of reliability, and map them to meaningful musical parameters, expands exponentially the creative possibilities open to performers without disrupting their established relationship with the harp, their instrumental technique, or their connection with the audience.

The MyoSpat case study demonstrates the validity of using standard instrumental gestures and techniques as a starting point to design interactions between performers and technology. Performers are in direct control of their sound, its transformations and processing. Accordingly, they are more likely to regard technology as an extension of their instrument and their performance practice, rather than as an external appendage.

Our findings so far are limited to the harp, but we are confident that this approach could be usefully applied to other musical instruments, by using the most appropriate bio-sensing technology for the specific gestures of each instrument. This view is supported by the research community (Arslan et al., 2006; Caramiaux, Donnarumma \& Tanaka, 2015; Donnarumma, Caramiaux \& Tanaka, 2013; Guerreiro, Lourenço, Silva \& Fred, 2014; Jaimovich, 2016; Tanaka, 2000), but also by the industry that produces the devices that inspired many of these works. The Myo ${ }^{\circledR}$ armband $^{19}$, Xth Sense ${ }^{\circledR 20}$, Emotiv $^{\circledR 21}$, Bitalino $^{\circledR 22}$, Olimex ${ }^{\circledR 23}$, MyoWear ${ }^{\circledR 24}$ and other bio-sensing Arduino ${ }^{\circledR}$ shields represent only a few examples of devices designed and developed for these purposes. The combination of growing knowledge and commercial availability of new tools for musical expression offers the promise to integrate fully technology in performance by making it progressively 
embodied within the performer's own practice. It is a welcome development towards a more humane, musical and expressive use of technology; one that clearly puts performers at the centre, and opens up exciting new avenues for artistic experimentation.

\section{Notes on Contributors}

\section{Balandino Di Donato}

Balandino is Lecturer in Creative Computing at University of Leicester and PhD candidate at Royal Birmingham Conservatoire's Integra Lab. He was Research Assistant at Goldsmiths, University of London, where he worked as sound and interaction designer for the development of a wireless EMG board for musical applications as part of the ERC-funded Project BioMusic.

He was previously Research Assistant at Centro Ricerche Musicali in Rome, where he worked on interactive sound art installation and performances, and Associate Researcher at Integra Lab for the development of Integra Live. He has developed software tools for musical expression such as the TUI Metis, Myo Mapper and Leap Mapper. His current research focuses on Music and Human-Computer Interaction.

\section{James Dooley}

A digital artist based in Birmingham, UK, James Dooley's (formuls) audiovisual interaction design examines approaches to combining audio, visual and environmental elements to create emergent forms. The individual components of his works play with the boundary between autonomy and synchrony, revealing their hidden connections and creating a metaenvironment.

His works have been exhibited internationally at festivals including: SPECTRA (MY), SonADA (UK), Electric Nights (GR), Slingshot (US). Recent works include formuls an algorithmically controlled audiovisual performance; \#medianatures an interactive work examining our increasing reliance upon technology and its future ecological impact; esthesis an AHRC commissioned audiovisual performance exploring hand-gesture controlled sound sculpting. James is currently Co-ordinator of Integra Lab, a research lab focused on music interaction design.

\section{Lamberto Coccioli}

Originally from Italy, in a career spanning over 30 years Lamberto has lectured and performed all over the world in his different roles as composer, researcher and electronic performer. From 1995 to 1999 he was Luciano Berio's assistant and in 2000 he became Head of Music Technology at Royal Birmingham Conservatoire where he directed the $€ 3.1 \mathrm{~m}$ EU-funded Integra project to support and promote composition and performance of music with live electronics (2005-2012), including the development of the Integra Live software. In 2012 Lamberto became Professor of Music and Technology, and in 2014 Associate Principal at Royal Birmingham Conservatoire, playing a key role in the design and construction of the new Conservatoire building and its innovative digital infrastructure. 


\section{References}

Arslan, B., Brouse, A., Castet, J., Lehembre, R., Simon, C., Filatriau, J. J. \& Noirhomme, Q. 2006. A Real Time Music Synthesis Environment Driven with Biological Signals (Vol. 2, pp. II-1172-II-1175). Proceedings of 2006 IEEE International Conference on Acoustics Speed and Signal Processing, IEEE. http://doi.org/10.1109/ICASSP.2006.1660557

Bullock, J., Coccioli, L., Dooley, J. \& Michailidis, T. 2013. Live Electronics in Practice: Approaches to training professional performers. Organised Sound, 18(02), 170-177. http://doi.org/10.1017/S1355771813000083

Caramiaux, B., Donnarumma, M. \& Tanaka, A. 2015. Understanding Gesture Expressivity through Muscle Sensing. ACM Transactions on Computer-Human Interaction, 21(6), 31:26. http://doi.org/10.1145/2687922

Chadefaux, D. 2013. Musician / instrument interaction: the case of the concert harp (1st ed.). Université Pierre et Marie Curie, Paris, France. Retrieved from https://tel.archivesouvertes.fr/tel-00828314v1

Chadefaux, D., Le Carrou, J. L. \& Fabre, B. 2013. A model of harp plucking. The Journal of the Acoustical Society of America, 133(4), 2444-2455. http://doi.org/10.1121/1.4792249

Chadefaux, D., Le Carrou, J. L., Fabre, B. \& Daudet, L. 2012a. Experimentally based description of harp plucking. The Journal of the Acoustical Society of America, 131(1), 844-855. http://doi.org/10.1121/1.3651246

Chadefaux, D., Wanderley, M. M., Le Carrou, J. L., Fabre, B. \& Daudet, L. 2012b. Experimental study of the musician / instrument interaction in the case of the concert harp. Proceedings of the Acoustics 2012, Nantes, France.

Chaigne, A. \& Kergomard, J. 2016. Acoustics of Musical Instruments (pp. 1-7). New York, NY: Springer New York. http://doi.org/10.1007/978-1-4939-3679-3

Dennett, J. I. 2015. Essential gesture. The University of Melbourne, Melbourne.

Desmet, F., Nijs, L., Demey, M., Lesaffre, M., Martens, J.-P. \& Leman, M. 2012. Assessing a Clarinet Player's Performer Gestures in Relation to Locally Intended Musical Targets. Journal of New Music Research, 41(1), 31-48. http://doi.org/10.1080/09298215.2011.649769

Di Donato, B. \& Bullock, J. 2015. gSPAT: Live sound spatialisation using gestural control (pp. 7-8). Proceedings of Student ThinkThank at the 21st International Conference on Auditory Display (ICAD 2015 STT), Graz, Austria. http://doi.org/10.13140/RG.2.1.2089.7128

Donnarumma, M., Caramiaux, B. \& Tanaka, A. 2013. Muscular Interactions (pp. 128-131). Proceedings of the International Conference on New Interfaces for Musical Expression, Kaist, Daejeon, Korea.

Eimert, H., Enkel, F. \& Stockhausen, K. 1954. Problems of electronic music notation (Fragen der Notation Elektronischer Musik). (D. A. Sinclair, Trans.) (Vol. 6, pp. 52-54). Ottawa, Canada: National Research Council of Canada. Retrieved from https://opasquet.fr/dl/texts/Eimert_Problems_of_Electronic_Music_Notation_1954.pdf

Emmerson, S. \& Smalley, D. 2001. Electro-Acoustic Music. In The new Grove dictionary of music and musicians (Vol. 8, pp. 58-65). New York Grove, London MacMillan.

Guerreiro, J., Lourenço, A., Silva, H. \& Fred, A. 2014. Performance Comparison of Low-cost Hardware Platforms Targeting Physiological Computing Applications. Procedia Technology, 17, 399-406. http://doi.org/10.1016/j.protcy.2014.10.204 
Huang, J.-Y. A. 2011. Effective Harp Pedagogy. (D. Sell, Ed.). University of Canterbury, Canterbury, United Kingdom.

Jaimovich, J. 2016. Emovere: Designing Sound Interactions for Biosignals and Dancers (pp. 316-320). Proceedings of the New Interfaces for Musical Expression, Brisbane, Australia. Kondonassis, Y. 2006. On Playing the Harp (2nd ed.). Carl Fischer LLC. Retrieved from https://books.google.co.uk/books?id=YzX9nrvtYIYC\&vq=raising\&source=gbs_navlinks_s

Le Carrou, J. L., Wahlen, E., Brasseur, E. \& Gilbert, J. 2008. Two dimensional finger-string interaction in the concert harp. The Journal of the Acoustical Society of America, 123(5), 3122-3122. http://doi.org/10.1121/1.2933044

Leman, M. 2010. Music, Gesture, and the Formation of Embodied Meaning. In R. I. Godøy \& M. Leman (Eds.), Musical Gestures: Sound, Movement, and Meaning (pp. 126-153). New York, USA: Routledge.

McNutt, E. 2003. Performing electroacoustic music: a wider view of interactivity. Organised Sound, 8(03), 297-304. http://doi.org/10.1017/S135577180300027X

Nicolls, S. 2010. Seeking Out the Spaces Between: Using Improvisation in Collaborative Composition with Interactive Technology. Leonardo Music Journal, 20, 47-55. http://doi.org/10.1162/LMJ_a_00012

Nicolls, S. 2011. Brief Thoughts on using Live Electronics: The Inside-out Piano and touring. eContact, 13(2). Retrieved from http://econtact.ca/13_2/nicolls_electronics.html

Pavlidou, M. 1997. A physical model of the string-finger interaction on the classical guitar. University of Wales, Cardiff, Cardiff, United Kingdom. Retrieved from http://ethos.bl.uk/OrderDetails.do?uin=uk.bl.ethos.273539

Rauschenberger, M., Schrepp, M., Perez-Cota, M., Olschner, S. \& Thomaschewski, J. 2013. Efficient Measurement of the User Experience of Interactive Products. How to use the User Experience Questionnaire (UEQ).Example: Spanish Language Version. International Journal of Interactive Multimedia and Artificial Intelligence, 2(1), 39. http://doi.org/10.9781/ijimai.2013.215

Salzedo, C. 1952. Modern Harp Technique: Gestures Have a Vital Part in Playing the Harp (interview with Carlos Salzedo), Etude Magazine 70(1),9. Theodore Presser Company

Streeck, J., Goodwin, C. \& LeBaron, C. 2011. Embodied Interaction in the Material World: An Introduction. In J. Streeck, C. Goodwin \& C. LeBaron (Eds.), Embodied Interaction, Language and Body in the Material World (Hardback, pp. 1-10). Cambridge, United Kingdom: Cambridge University Press.

Tanaka, A. 2000. Musical Performance Practice on Sensor-based Instruments. In M. Battier \& M. M. Wanderley (Eds.), Trends in Gestural Control of Music (pp. 389-406). IRCAM Centre Pompidou.

Visi, F., Schramm, R. \& Miranda, E. 2014. Use of Body Motion to Enhance Traditional Musical Instruments (pp. 601-604). Proceedings of the International Conference on New Interfaces for Musical Expression, London, United Kingdom.

Wang, G. \& d'Escrivan, J. 2011. A history of programming and music. In N. Collins (Ed.), The Cambridge Companion to Electronic Music (pp. 55-86). Cambridge: Cambridge University Press. http://doi.org/10.1017/CCOL9780521868617.006

Wigham, P. \& Boehm, C. 2016. Exploiting Mimetic Theory for Instrument Design (pp. 1-4). Proceedings of the International Computer Music Conference, Utrecht, Netherlands.

Wilkie, K., Holland, S. \& Mulholland, P. 2009. Evaluating Musical Software Using Conceptual 
Metaphors (pp. 232-237). Proceedings of BCS Human-Computer Interaction $\mathrm{HCl}$, Cambridge, United Kingdom.

Wilkie, K., Holland, S. \& Mulholland, P. 2010. What Can the Language of Musicians Tell Us about Music Interaction Design? Computer Music Journal, 34(4), 34-48.

http://doi.org/10.1162/COMJ_a_00024

\section{Musical Works}

Álvarez, J. 1989. Acuerdos por diferencia, for harp and electroacoustic sounds.

Berio, L. 1963. Sequenza II, for harp.

Berio, L. 1967. Sequenza VI, for viola.

Berio, L. 1984. Sequenza $X$, for trumpet.

Boulez, P. 1988. Répons, for soloists, ensemble and live electronics.

Cendo, R. 2007. Octa 7, for harp. On a choreography by Olivia Grandville.

Ellis, J. R., 2014. Weav-Weav-Weaving I, II and III, for harp and interactive electronics.

Graugaard, L. 2008. Sound Shapes, for harp and interactive computer.

Kishino, M. 2005. Éclosion, for harp and 9-channel live electronics.

Roy, A. 2017. FlyByNo - The Families (Lumeris Theme), for harp and live electronics.

Risset, J. 2004. Echappées, for celtic harp.

Saariaho, K. 1991. Fall, for harp and electronics.

Spiropoulos, G. 2015. Roll...'n roll...'n roll, for prepared harp and electronics.

Steen-Andersen, S. 2011. History of My Instrument, for prepared harp and video.

Stockhausen, K. 1964. Mixtur, No. 16, for orchestra, 4 sine-wave generators and 4 ring modulators.

Stockhausen, K. 1966. Mikrophonie II, No. 17, for choir, Hammond organ or synthesiser and 4 ring modulators.

Turner, E. 2016. The Wood and the Water, for harp and electronics.

\footnotetext{
${ }^{1}$ Chemins I for harp and orchestra (1965) is based on Sequenza I/ for solo harp.

${ }^{2}$ Tempo Reale is the music research and production centre founded by Berio in Florence in 1987.

http://www.temporeale.it

${ }^{3}$ https://youtu.be/gJOFqnLiyoY

${ }^{4}$ https://www.leapmotion.com/

${ }^{5}$ http://interlude.ircam.fr/

${ }^{6}$ https://goo.gl/xa2jb3

7 https://cycling74.com/products/max/

8 http://x-io.co.uk/x-imu/

${ }^{9}$ https://vimeo.com/16665607

${ }^{10}$ https://goo.gl/xa2jb3

${ }^{11} \mathrm{http}: / /$ www.balandinodidonato.com/works/myospat/

12 https://goo.gl/FFzbkG

${ }^{13}$ https://www.myo.com/

${ }^{14}$ http://www.balandinodidonato.com/myomapper

15 https://puredata.info/

${ }^{16} \mathrm{https} / / /$ vimeo.com/128395577

17 https://vimeo.com/174099457

18 https://youtu.be/02jPgh4Cvxo
} 
${ }^{19} \mathrm{https}: / /$ www.myo.com/

${ }^{20}$ http://www.xth.io/

${ }^{21}$ https://www.emotiv.com/

22 http://www.bitalino.com/

${ }^{23} \mathrm{https://www.olimex.com/Products/Duino/Shields/}$

${ }^{24}$ https://www.adafruit.com/product/2699 